\title{
Professor Barry N. Rewcastle (1931-2014)
}

We are saddened by the passing of Dr. Barry Rewcastle in January 2014. Immigrating to Canada from the U.K., he is now recognized as one of the major contributors to the development of modern Canadian neuropathology. After several years at the University of Toronto, he moved to the University of Calgary and became Head of the Department of Pathology and Laboratory Medicine for two highly successful five year terms. I was on faculty during Dr. Rewcastle's tenure at the University of Calgary from 1981, and had the privilege of seeing him on several occasions even after his retirement in 2000. He was elected as the Representative of the Canadian Association of Neuropathologists (CANP) to the International Congress of Neuropathology in 1965 and later served as President of the CANP from 1976 to 1979.

Barry attended the Worcester Grammar School on the River Severn, in western England, U.K. from 1943-49. He went on to the University of St. Andrews 194955 , half-joking that all the best positions at Oxford and Cambridge were filled with soldiers returning from the war. He then immigrated to Canada, starting in Vancouver but later deciding to further his specialty training at the University of Toronto.

I always respected and admired Barry, both professionally and personally. Apart from his many contributions to the knowledge base of neuropathology and his acumen and precision as a diagnostic neuropathologist, he was dignified, generous to colleagues and trainees with his time, and a kind individual with admirable honesty who cared deeply about faculty members and trainees under his leadership. He was genuinely supportive and interested in the career progress of each of us and tried to facilitate our academic pursuits. Our achievements in research, publications, presentations and teaching programmes for residents were a source of pride to him, as he saw them not only as individual accomplishments but as collective reflections on his whole department.

He always treated his faculty with respect. He held annual meetings with each of the neuropathologists to inquire about our research, our goals for the coming academic year, and problems which he might help us resolve. If ever there was a question posed or uncertainty by a faculty member about a diagnosis of a surgical biopsy or autopsy, he would suggest reviewing the case together or with another colleague with expertise to resolve the issue in a collegial manner. He also showed his maturity in administering the Department by appointing competent faculty to positions of responsibility, and then expecting them to carry out their charge without interference. Despite his demanding schedule as Department Head, he also dedicated considerable time and remarkable patience to teaching not only residents in neuropathology and anatomical pathology, but also those taking rotations on the Neuropathology Service from Adult and Paediatric Neurology, Neurosurgery and Neuroradiology. Many describe their experience as instrumental in maturing their perspective and understanding of neurological disease. One of his neuropathology trainees at the University of Toronto was Dr. Bernadette Curry, who also was recruited to Calgary to join the faculty and who eventually became Head of the Section of Neuropathology for many years before her recent retirement. Other neuropathologists who formed our group at the University of Calgary under Barry's leadership, and whom Barry also encouraged and supported, included Arthur Clark, David George and Roland N. Auer. Barry was succeeded as Pathology Department Head by Dr. Hallgrimur Benediktsson.

We always enjoyed the annual Christmas holiday party which he and his wife hosted in their home. He had difficult challenges in his personal life because of his wife's chronic illness. His dedication to his wife and her special needs due to suffering with multiple sclerosis led him to do additional training in immunology in the laboratory of Dr. V. Wee Yong, Canada Research Chair in Neuroimmmunology, and to develop a special research interest in inflammatory encephalopathies. He demonstrated the utility of minocycline as an efficient immunomodulator in EAE that suppresses the histological signs of the disease, and published these findings, with colleagues, in a landmark article (Brain 2002;125:1297-1308); the results of this paper now form the basis for clinical trials of minocycline in MS across 12 Canadian centres. Always a popular member of the Canadian Association of Neuropathologists amongst his national colleagues, he was highly respected internationally as well. His dignity and dry understated British sense of humour, 
often ironic but never sarcastic or mean-spirited, were legendary amongst the most senior faculty and the most junior residents alike.

I will always remember Barry Rewcastle, most of all for the encouragement he personally gave me year after year, in fostering my pursuit of fetal and developmental neuropathology, similar to his tutelage of other junior and mid-career academic neuropathologists in his charge. His support of my career development was major, for which I will always be grateful. He was one of the most kind-hearted and patient colleagues and teachers I have known. He was indeed a friend as well as a colleague, and a model departmental head, for whom I was both proud and humbly grateful to be included as part of his faculty. A person like Barry Rewcastle transcends death.

\section{ACKNOWLEDGEMENT}

This obituary was originally commissioned by and published in Brain Pathology. Republication in the CJNS is with permission of the Editor-in-Chief of that journal, for which we are grateful.

Harvey B. Sarnat Pathology (Neuropathology) and Clinical Neurosciences University of Calgary Faculty of Medicine and Alberta Children's Hospital Research Institute Calgary, Alberta, Canada Email: harvey.sarnat@albertahealthservices.ca 